\title{
Diversidad y composición florística del Bosque Los Búhos ubicado en la provincia de Chimborazo, Ecuador
}

\section{(Diversity and floristic composition of the Los Búhos Forest located in the province of Chimborazo, Ecuador)}

\author{
Patricio Lozano ${ }^{1}$, Aracely Armas ${ }^{1}$, Martha Gualán¹, Miguel Guallpa ${ }^{1}$
}

\begin{abstract}
Resumen:
Para promover procesos de conservación es fundamental conocer la biodiversidad objeto de análisis. En tal sentido, el objetivo del presente trabajo fue determinar la composición, diversidad e importancia florística del Bosque Los Búhos para generar una línea base que permita el manejo del recurso con propósitos académicos. Por tal motivo, en esta investigación se realizó una descripción de la composición florística, se determinaron los índices de biodiversidad alfa ( $\alpha$ ) y beta $(\beta)$, finalmente se calculó la importancia ecológica de las especies (IVI's). Los datos indican que la composición florística del bosque se encuentra conformada en tres estratos por 56 especies, 18 órdenes y 27 familias. El estrato arbóreo presenta una biodiversidad media (2,534Margalef) y dominancia alta (0,8367-Simpson), el estrato arbustivo tiene baja biodiversidad (1,811-Margalef) y baja dominancia (0,4441-Simpson), y el estrato herbáceo presenta biodiversidad media (3,882-Margalef) y dominancia alta $(0,7101$ Simpson). Las especies con el mayor IVI's para el estrato arbóreo son Mimosa quitensis (Benth. 1848), Acacia retinodes (Schltdl.1847), y Tecoma stans (L. Juss. ex Kunth. 1819). Para el estrato arbustivo son Agave americana (L. 1753), Lantana megapotamica (Spreng. Tronc. 1974), Retama sphaerocarpa (L. Boiss. 1840) y Opuntia cylindrica (Lam. DC. 1828). Finalmente para el estrato herbáceo es Carpobrotus edulis (L. N.E.Br. 1926).
\end{abstract}

Palabras clave: importancia ecológica, estepa espinosa montano bajo, biodiversidad, conservación

\begin{abstract}
:
To promote conservation processes it is essential to know the biodiversity under analysis. The objective of the present work was to determine the composition, diversity and floristic importance of El Bosque Los Búhos to generate a baseline that allows the management of the resource for academic purposes. A description of the floristic composition was made, the alpha ( $\alpha)$ and beta $(\beta)$ biodiversity indexes were determined and the ecological importance of the species (IVI's) was calculated. The data indicate that the floristic composition of the forest is formed in three strata by 56 species, 18 orders and 27 families. The arboreal stratum presents a biodiversity average $(2,534-$ Margalef) and high dominance (0,8367-Simpson), the shrub layer has low biodiversity (1,811-Margalef) and low dominance (0,4441-Simpson), and the herbaceous stratum presents biodiversity average (3,882-Margalef) and high dominance (0,7101-Simpson). The species with the highest IVI's for the arboreal stratum are Mimosa quitensis (Benth.1848), Acacia retinodes (Schltdl.1847), y Tecoma stans (L. Juss. ex Kunth. 1819). For the shrub layer are Agave americana (L.1753), Lantana megapotamica (Spreng. Tronc. 1974), Retama sphaerocarpa (L. Boiss. 1840) y Opuntia cylindrica (Lam. DC. 1828). Finally for the herbaceous stratum is Carpobrotus edulis(L.N.E.Br. 1926).
\end{abstract}

Keywords: ecological importance, low montane thorny steppe, biodiversity, conservation

\footnotetext{
${ }^{1}$ Escuela Superior Politécnica de Chimborazo, Riobamba, Ecuador (plozano@espoch.edu.ec).
} 


\section{Introducción}

En las últimas décadas es notable el interés por la conservación de la diversidad biológica como uno de los objetivos de la gestión forestal (Hernández \& Giménez, 2016), ya que los bosques son los ecosistemas terrestres más importantes del planeta por su extensión, su complejidad ecológica, biodiversidad y endemismo; además que desempeñan funciones ambientales de gran importancia a distintas escalas (Ruiz, García, \& Sayer, 2007); desde una perspectiva histórica es necesario encontrar un equilibrio entre conservación y uso de los bosques ya que de esta forma se garantizará la contribución de los múltiples beneficios que generan estos sistemas a los componentes ambiental, social y económico de un territorio (FAO, 2012).

Los bosques cubren el $31 \%$ de la superficie global, es decir 4000 millones de hectáreas (FAO, 2009). En América Latina y el Caribe los bosques cubren el $22 \%$ de la superficie: 860 millones de hectáreas, de estas el 97\% se encuentran en América del Sur: 831,5 millones de hectáreas (Cordero, 2011). En Ecuador los bosques cubren cerca de 9'599 687,7 hectáreas distribuyéndose a lo largo de las cuatro regiones naturales (Grijalva, Checa, Ramos, Barrera, \& Limongi, 2012).

Dentro de los sistemas boscosos la variedad de formas de vida, estratos arbóreos, así como la variedad de especies animales son indicadores de la existencia de diversos hábitats y ecosistemas (Kutschker, Brand, \& Miserendino, 2009). Una de estas formas de vida es la denominada zona Estepa Espinosa Montano Bajo que cubre un área de 117075 hectáreas, lo cual representa el $0,45 \%$ de la superficie total del país (Holdridge, 1967). Esta zona de vida está presente en el Callejón Interandino, en las provincias de: Pichincha (Guayllabamba, Jerusalén, San Antonio), Cotopaxi (Saquisilí, La Victoria, Latacunga), Tungurahua (Yambo, Ambato, Cevallos, Totoras) y Chimborazo (Licto, Licán, Guano, Cubijles, Riobamba, San Luis, Cebadas, Sibambe, Alausí y Guasuntos), formando llanuras, barrancos y valles muy secos.

Se localiza en gradientes altitudinales que van desde los 2000 hasta los $2900 \mathrm{~m}$ s.n.m. en las vertientes occidentales, y en las vertientes orientales de Los Andes llega hasta a los 3000 m s.n.m. Las temperaturas en estas zonas varían entre los 12 y $18^{\circ} \mathrm{C}$, y reciben una precipitación media anual entre los 250 y 500 mm (Rivas , Alarcón , Espinosa , Carrillo , \& Villamarín, 2005).

La vegetación dominante en la Estepa Espinosa Montano Bajo es la especie arbórea Acacia macracantha (Humb. \& Bonpl. ex Willd. 1806- Guarango), los arbustos Dodonaea viscosa (L. Jacq. 1760- chamana), Opuntia soederstromiana (Britton \& Rose 1919-cactus), y la herbácea Datura stramonium (L. 1753- Chamico), (Mendoza, 2011). Una especie típica de esta formación es el Prunus serotina (Ehrh (Cav.) Mc Vaugh, 1951- Capulí); que se cultiva en Cubijes y Cebadas (Chimborazo).

Además, se puede afirmar que los bosques juegan un papel integral en la ecología del medio natural ya que regulan los flujos de humedad atmosférica (Blanco, 2017), debido a su biodiversidad (FAO, 2015). Sin embargo, Ecuador registra una de las tasas más altas de deforestación en Latinoamérica, con una pérdida anual de más de 70000 Has de bosques (FAO, 2014).

Bajo este contexto, el análisis de la composición florística permite comprender el estado ecológico y necesidades de manejo de un bosque para promover procesos que contribuyan a mantener la biodiversidad (Torres, 2014), ya que algunos estudios indican que la diversidad y composición florística de los bosques están influenciadas directamente por el clima, el drenaje, la topografía, los suelos y la actividad antrópica (Quinto \& Moreno, 2014).

Adicionalmente, los estudios de diversidad y composición florística son necesarios por cuanto permiten conocer las especies que conforman un área, así como su distribución y fisonomía (Ceroni, 2003), ya que además son atributos de las comunidades ecológicas que contribuyen a la compresión y comparación con otros sistemas (Macia \& Fuertes, 2008). La diversidad está conformada por la riqueza y equidad de especies (Cano \& 
Stevenson, 2009), mientras que la composición se determina mediante la cuantificación del Índice Valor de Importancia (IVI) de las especies, que consiste en la sumatoria de los valores relativos de densidad, frecuencia y dominancia e indica la importancia ecológica relativa de las especies de plantas en una comunidad (Soler, Berroterán, Gil, \& Acosta, 2012).

El Bosque Los Búhos con una superficie de 3,9 hectáreas se encuentra al suroeste de la ciudad de Riobamba, es parte de la Facultad de Recursos Naturales de la Escuela Superior Politécnica de Chimborazo y su principal función es proveer de espacios para la realización de prácticas y estudios académicos; así también de hábitat para especies que llegan a la zona. Athene cunicularia (Molina, 1782- Búho terrestre), Zenaida auriculata (Des Murs, 1847-Tórtola orejuda), Zonotrichia capensis (Statius Müller, 1776- Chingolo), Phrygilus plebejus (Tschudi, 1844 -Frijilo pechicinéreo), Catamenia analis (d'Orbigny and Lafresnaye, 1837 -Semillero colifajeado) son las especies faunísticas de mayor presencia en el bosque (Pérez, 2017). Sin embargo de esta función, no cuenta con información relevante y poco se conoce acerca de su estructura, composición y diversidad florística, que ayuden a entender su dinámica y funcionamiento. Ante esta situación el estudio de las características florísticas y estructurales se convierte en una necesidad imperante, ya que contribuirá a una adecuada planificación para la conservación de los recursos existentes en este lugar.

Para atender esta situación, la presente investigación busca responder las siguientes interrogantes: ¿cuál es la composición florística del Bosque?, ¿cuál es la diversidad alfa $(\alpha)$ y beta $(\beta)$ del Bosque? y ¿cuál es la importancia ecológica de las especies (IVI's) de flora del Bosque?. Para resolver estas interrogantes se formularon tres objetivos: a) describir la composición florística del Bosque, b) determinar los índices de diversidad alfa $(\alpha)$ y beta $(\beta)$ del Bosque, y c) calcular el IVI de las especies de flora del Bosque. Es así que el presente trabajo busca generar una línea base para impulsar procesos de conservación y manejo del Bosque, asociado con la realización de prácticas y estudios académicos.

\section{Materiales y métodos}

\section{1. Área de estudio}

El presente trabajo de investigación se realizó en la jurisdicción de la Escuela Superior Politécnica de Chimborazo; el estudio se centró en el Bosque Los Búhos (tal como se muestra en la Figura 1) cuyas coordenadas son: Longitud: $757582 \mathrm{~m}$, Latitud: 9817537m, Altitud: 2850 m s.n.m.

El Bosque Los Búhos presenta una temperatura promedio de $13,9{ }^{\circ} \mathrm{C}$, una precipitación anual de 385,4 $\mathrm{mm}$ y una humedad relativa promedio de $74,5 \%$ (EA$\mathrm{ESPOCH}, 2016)$. En cuanto a rasgos físicos, el suelo del Bosque presenta una textura franco arenoso, una densidad aparente de $1,35 \mathrm{gr} / \mathrm{cc}$, una densidad real de 2,10 gr/cc, una humedad gravimétrica de $13,90 \%$ y una porosidad total de $35,30 \%$, mientras que sus rasgos químicos se caracterizan por presentar bajos niveles de nitrógeno $(9,6 \mathrm{ug} / \mathrm{ml})$, niveles bajos de fósforo $(15,5 \mathrm{ug} / \mathrm{ml})$, altos niveles de potasio $(264,0)$, niveles medios de materia orgánica $(4,0)$, y un pH neutro $(7,47)$, (Dpto. Sue. Frn- ESPOCH, 2015).

\subsection{Métodos}

La presente investigación midió de forma independiente las variables e indicadores para describir la composición florística, determinar los índices de diversidad alfa ( $\alpha$ ) y beta $(\beta)$ y posteriormente calcular el IVI de las especies de flora de los estratos arbóreo, arbustivo y herbáceo del Bosque. Para cumplir este propósito se emplearon métodos y técnicas de investigación de campo, aplicada y documental, las cuales se describen por objetivo. 


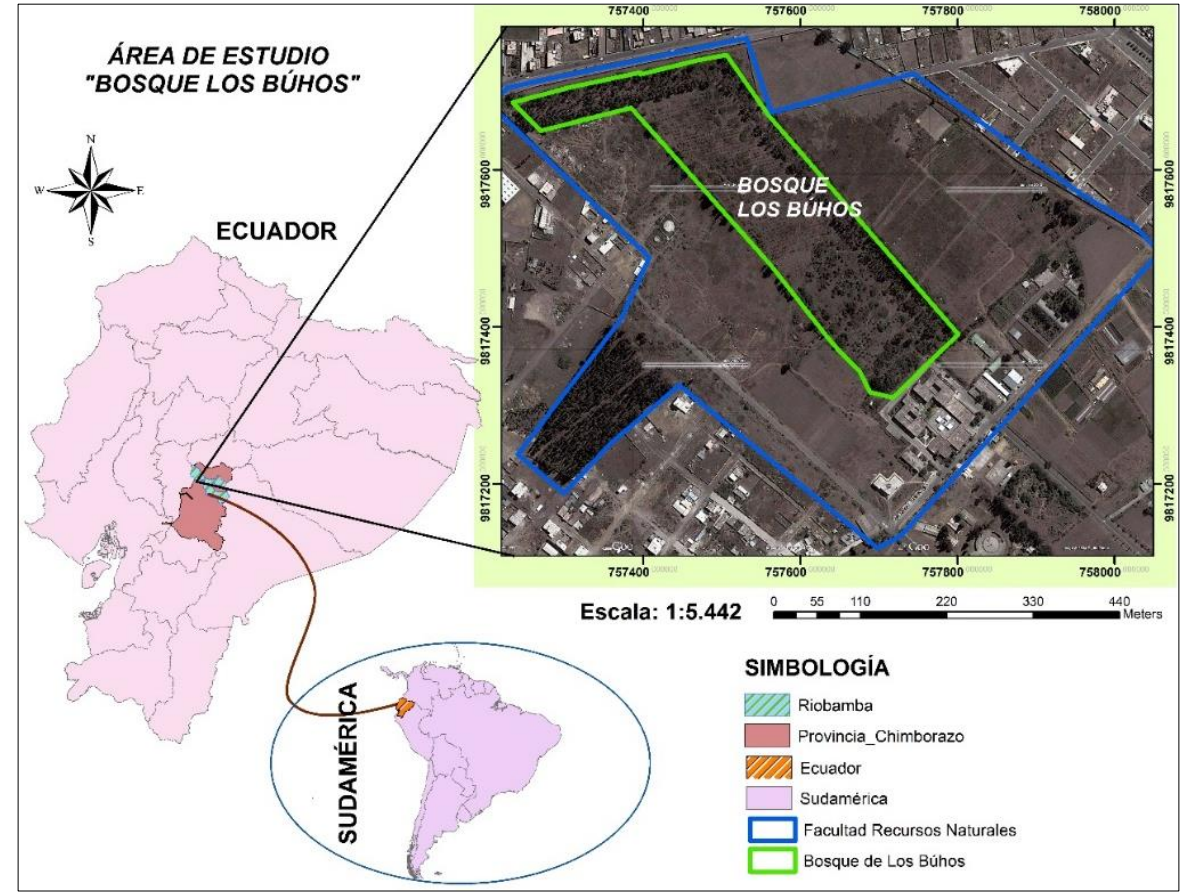

Figura 1. Área de estudio Bosque Los Búhos

\subsubsection{Descripción de la composición florística}

Se aplicaron dos métodos: a) método de investigación de campo en un área muestral de $4000 \mathrm{~m}^{2}$ (tal como se muestra en la Figura 2), dividida en 4 transectos $(10 \times 100 \mathrm{~m}$ ) y estos a su vez divididos en subtransectos empleados para muestrear: 1) arbustos (2 subtransectos de $4 \times 25 \mathrm{~m}$ ), 2) herbáceas (4 subtransectos de $1 \times 4 \mathrm{~m}$ ), y el área restante se utilizó para muestrear árboles (IAVH, 2006), en los cuales se identificaron especies arbóreas, arbustivas y herbáceas mismas que se registraron en fichas de inventario de campo; y b) el método de investigación documental y técnicas comparativas para la identificación de especies que no pudieron ser reconocidas en el campo, para lo cual se fotografiaron según sus características morfológicas, para luego ser identificadas con la ayuda de la colección del Herbario de la Escuela Superior Politécnica de Chimborazo (CHEP) y con el apoyo de especialistas botánicos.

\subsubsection{Análisis de diversidad alfa y beta}

Para determinar la diversidad del bosque se aplicaron los índices diversidad alfa ( $\alpha$ ): índice de (Shannon, 1949) $\left(\mathrm{H}^{\prime}=-\Sigma \mathrm{pi}(\mathrm{In} \mathrm{pi})\right)$, índice de (Simpson, 1960), ( $\left.\mathrm{D}=1-\Sigma(\mathrm{pi}) 2\right)$, e índice de (Margalef, 1958$),(\mathrm{DMg}=\mathrm{S}-1 / \mathrm{lnN})$, así como los índices de diversidad beta $(\beta)$ : índice de Bray-Curtis; los cuales se calcularon mediante el método de investigación aplicada a través de la utilización del software Past 3,15 (Hammer, Harper, \& Ryan, 2013); mientras que para la curva de acumulación de especies se trabajó en el (Software Estimates 9,10, 2016) y el software Microsoft Excel 2013. El listado de especies con su número de individuos se ingresó en el Software Past 3,15 tanto para el cálculo de biodiversidad por transecto y por estrato. Para la interpretación de resultados se utilizó (Cerón, 2003; Murillo, 2002; Moreno, 2001).

\subsubsection{Determinación de la composición y estructura vegetal}

La composición florística del Bosque se determinó mediante la cuantificación del IVI de las especies, la cual consistió en la sumatoria de los valores relativos de la densidad o 
abundancia relativa $(\mathrm{Ar})$, frecuencia relativa $(\mathrm{Fr})$ y dominancia relativa $(\mathrm{Dr})$, conforme lo sugiere (Soler, Berroterán, Gil, \& Acosta, 2012).

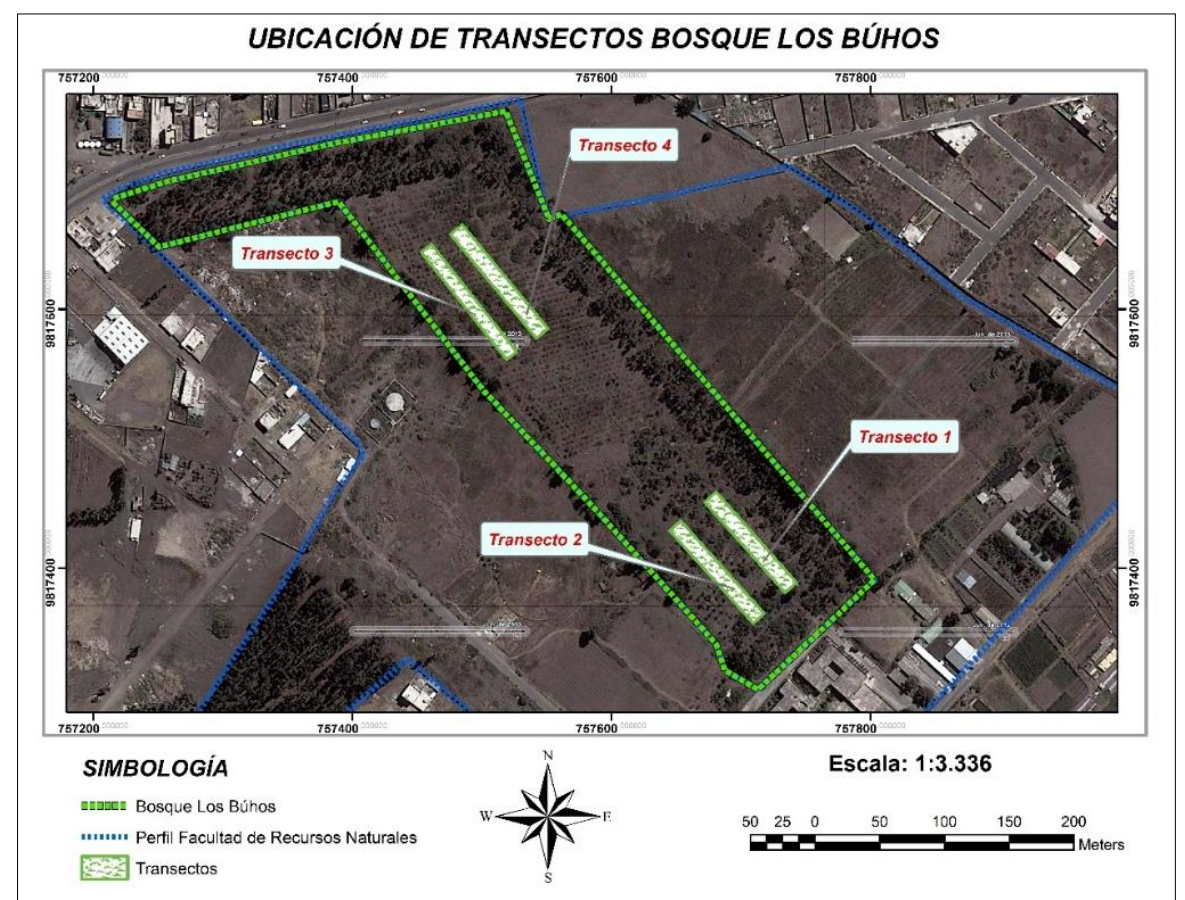

Figura 2. Ubicación de transectos Bosque Los Búhos

\section{Resultados}

\subsection{Descripción de la composición florística del Bosque}

\subsubsection{Estrato arbóreo}

La composición florística del Bosque Los Búhos para el estrato arbóreo se encuentra determinada por 13 especies, 12 familias y 11 órdenes. Las familias con mayor número de especies son: Fabaceae con el 30,77\% (cuatro especies) y Budlejaceae con el $15,38 \%$ (dos especies); las 7 familias restantes representan con el 7,69\% (una especie cada familia), el $53,85 \%$ del total de las especies.

Los órdenes que presentan un mayor número de familias en el estrato arbóreo del Bosque son: Fabales y Lamiales con el 22,22\% (dos familias cada orden), los cinco órdenes restantes reflejan un porcentaje de $11,11 \%$ cada uno, es decir cada orden posee una familia.

Adicionalmente según la categoría UICN la especie Oreopanax ecuadorensis (Seem.1865- Puma maki) está catalogada como Preocupación Menor (LC), mientras que las demás especies se encuentran como No Evaluadas (NE), como se muestra en la Tabla 1.

\subsubsection{Estrato arbustivo}

La composición florística del Bosque para el estrato arbustivo se encuentra determinada por 11 especies, 6 familias y 6 órdenes. Las familias con mayor número de especies son: Cactacea con el $27,27 \%$ (tres especies), seguidas de las familias Agavaceae, Fabaceae, Verbenaceae con el 18,18\% (dos especies cada familia); las dos familias restantes representan el 9,09\% (una especie cada familia) del total de las especies.

Los órdenes para el estrato arbustivo del Bosque Los Búhos reflejan igualdad por cuanto representan el 16,67\% (una familia cada uno de los órdenes). Adicionalmente según 
la categoría UICN las especies Cleistocactus sepium (Kunth. F.A.C. Weber, 1904- Cactus) y Opuntia soederstromiana (Britton \& Rose 1919- Tuna) están catalogadas como Preocupación Menor (LC), mientras que las demás especies se encuentran como No Evaluadas (NE), como se muestra en la Tabla 2.

Tabla 1. Riqueza florística del estrato arbóreo del Bosque Los Búhos

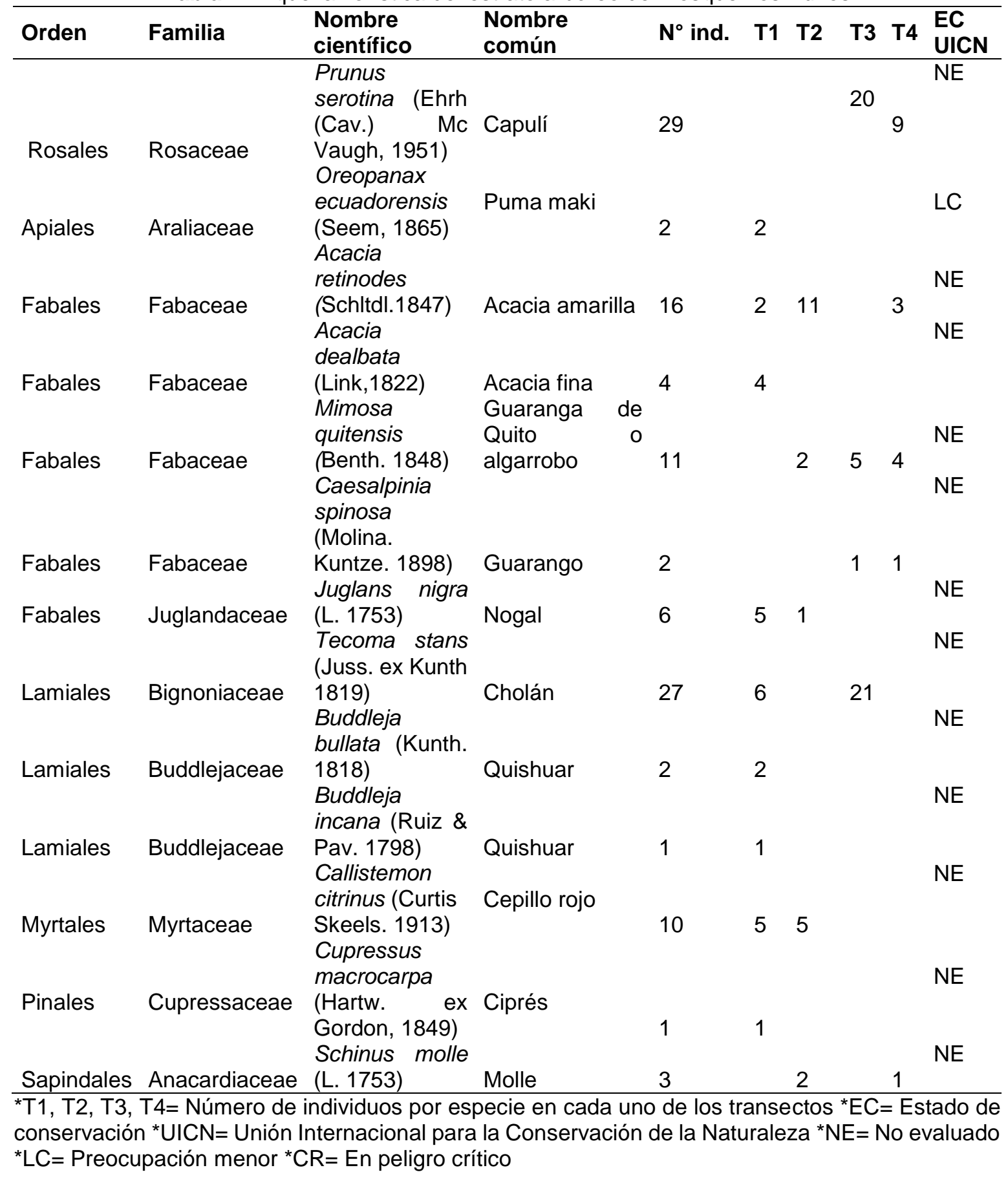

\subsubsection{Estrato herbáceo}

La composición florística del Bosque para el estrato herbáceo se encuentra determinada por 32 especies, 16 familias y 12 órdenes. Las familias con mayor número de especies son: con el 25\% Poaceae (ocho especies), con el 18,75\% Asteraceae (seis especies) y con el 6,25\% Fabaceae, Crassulaceae y Solanaceae (dos especies cada 
familia), las dos familias restantes representan el $31,25 \%$ (una especie cada familia) del total de las especies.

Los órdenes que presentan un mayor número de familias en el estrato herbáceo del Bosque son: Poales y Polypodiales con el $18,75 \%$ (tres familias cada orden), mientras que los 10 órdenes restantes reflejan un porcentaje de 6,25\% cada uno; es decir cada orden posee una familia.

Tabla 2. Riqueza florística del estrato arbustivo del Bosque Los Búhos

\begin{tabular}{|c|c|c|c|c|c|c|c|c|c|}
\hline Orden & Familia & $\begin{array}{l}\text { Nombre } \\
\text { científico }\end{array}$ & $\begin{array}{l}\text { Nombre } \\
\text { común }\end{array}$ & $N^{\circ}$ ind. & T1 & T2 & T3 & T4 & $\begin{array}{l}\text { EC } \\
\text { UIC } \\
N\end{array}$ \\
\hline Asparagales & Agavaceae & $\begin{array}{l}\text { Agave } \\
\text { americana } \\
\text { (L.1753) }\end{array}$ & Àgave azul & 184 & 123 & 45 & 16 & & $\mathrm{NE}$ \\
\hline Asparagales & Agavaceae & $\begin{array}{l}\text { Furcraea } \\
\text { foetida } \\
\text { Haw } 1812\end{array}$ & $\begin{array}{l}\text { Agave } \\
\text { verde } \\
\text { pita }\end{array}$ & 4 & 1 & 2 & 1 & & NE \\
\hline Caryophyllales & Cactaceae & $\begin{array}{l}\text { Opuntia } \\
\text { cylindrica } \\
\text { (Lam.) DC. } \\
\text { 1828) }\end{array}$ & $\begin{array}{l}\text { Cactus o } \\
\text { Tuna }\end{array}$ & 7 & 1 & & & 6 & $\mathrm{NE}$ \\
\hline \multirow[t]{2}{*}{ Caryophyllales } & Cactaceae & $\begin{array}{l}\text { Cleistocactus } \\
\text { sepium } \\
\text { (Kunth. F.A.C. } \\
\text { Weber, 1904) }\end{array}$ & Cactus & 3 & & & 3 & & LC \\
\hline & Cactaceae & $\begin{array}{l}\text { Opuntia } \\
\text { soederstromia } \\
\text { na (Britton \& } \\
\text { Rose 1919) }\end{array}$ & Tuna & 4 & 1 & & 3 & & LC \\
\hline Fabales & Fabaceae & \begin{tabular}{ll}
\multicolumn{2}{l}{ Retama } \\
sphaerocarpa \\
(L. $\quad$ Boiss. \\
1840)
\end{tabular} & $\begin{array}{l}\text { Retama } \\
\text { amarilla }\end{array}$ & 11 & & 7 & & 4 & $\mathrm{NE}$ \\
\hline Fabales & Fabaceae & $\begin{array}{l}\text { Dalea } \\
\text { coerulea (L.f. } \\
\text { Schinz \& } \\
\text { Thell. 1913) }\end{array}$ & Izo & 1 & & & & 1 & NE \\
\hline Lamiales & Verbenaceae & $\begin{array}{l}\text { Lantana } \\
\text { megapotamic } \\
\text { a (Spreng. } \\
\text { Tronc. 1974) }\end{array}$ & $\begin{array}{l}\text { Lantana } \\
\text { morada }\end{array}$ & 25 & 1 & 5 & 16 & 3 & $\mathrm{NE}$ \\
\hline Lamiales & Verbenaceae & $\begin{array}{l}\text { Lantana } \\
\text { camara } \\
\text { (L.1753) }\end{array}$ & Supirrosa & 4 & & 4 & & & $\mathrm{NE}$ \\
\hline Poales & Poaceae & $\begin{array}{l}\text { Cortaderia } \\
\text { Selloana } \\
\text { (Schult. \& } \\
\text { Schult.f.) } \\
\text { (Asch. \& } \\
\text { Graebn. 1900) }\end{array}$ & $\begin{array}{l}\text { Sixe o } \\
\text { carrizo de } \\
\text { la Pampa }\end{array}$ & 1 & & 1 & & & $\mathrm{NE}$ \\
\hline Sapindales & Sapindaceae & $\begin{array}{l}\text { Dodonaea } \\
\text { viscosa } \\
\text { Jacq. 1760) }\end{array}$ & Chamana & 6 & 2 & & 2 & 2 & $\mathrm{NE}$ \\
\hline
\end{tabular}


Adicionalmente según la categoría UICN las especies Lupinus pubescens (Benth. 1846 -Falso chocho), Crotalaria pumila (Ortega. Standley,P.C. \& Steyermark,J.A 1946Tronadora) y Cyperus polystachyos (Rottb, 1773- Flatsedge) están catalogadas como Preocupación Menor (LC) la especie Bidens andicola (Kunth,1820- Ñachag) está catalogada como En Peligro Crítico (CR), mientras que las demás especies se encuentran como No Evaluadas (NE), como se muestra en la Tabla 3.

Tabla 3. Riqueza florística del estrato herbáceo del Bosque Los Búhos

\begin{tabular}{|c|c|c|c|c|c|c|c|c|c|}
\hline Orden & Familia & $\begin{array}{l}\text { Nombre } \\
\text { científico }\end{array}$ & $\begin{array}{l}\text { Nombre } \\
\text { común }\end{array}$ & $N^{\circ}$ ind. & T1 & T2 & T3 & T4 & $\begin{array}{l}\text { EC } \\
\text { UIC }\end{array}$ \\
\hline Asterales & Asteraceae & $\begin{array}{ll}\text { Bidens } & \text { pilosa } \\
(\text { L.1753) } & \end{array}$ & Amor seco & 1 & & 1 & & & $\mathrm{NE}$ \\
\hline Asterales & Asteraceae & $\begin{array}{l}\text { Bidens andicola } \\
\text { (Kunth 1820) }\end{array}$ & Ñachak & 41 & 15 & 1 & & 25 & CR \\
\hline Asterales & Asteraceae & $\begin{array}{l}\text { Gnaphalium } \\
\text { uliginosum } \\
\text { (L.1753) }\end{array}$ & $\begin{array}{l}\text { Orejas } \\
\text { conejo }\end{array}$ & 74 & 25 & 9 & 9 & 31 & NE \\
\hline Asterales & Asteraceae & $\begin{array}{l}\text { Tagetes } \\
\text { coronopifolia } \\
\text { (Willd. 1815) }\end{array}$ & Tagetes & 4 & & 1 & 3 & & NE \\
\hline Asterales & Asteraceae & $\begin{array}{l}\text { Gnaphalium } \\
\text { pensylvanicum } \\
\text { (Willd. 1768) }\end{array}$ & Macela & 1 & & & & 1 & $\mathrm{NE}$ \\
\hline Asterales & Asteraceae & $\begin{array}{l}\text { Lactuca serriola } \\
\text { (L.1756) }\end{array}$ & Lechuguilla & 1 & & & 1 & & $\mathrm{NE}$ \\
\hline Brassicales & Brassicaceae & $\begin{array}{l}\text { Lobularia } \\
\text { marítima (L. } \\
\text { Desv, 1814) }\end{array}$ & Aliso de mar & 3 & 3 & & & & NE \\
\hline Caryophyllales & Aizoaceae & $\begin{array}{l}\text { Carpobrotus } \\
\text { edulis (L.) } \\
\text { (N.E.Br. 1926) }\end{array}$ & Garra de tigre & 1139 & 685 & $\begin{array}{l}45 \\
4\end{array}$ & & & $\mathrm{NE}$ \\
\hline Poales & Poaceae & $\begin{array}{l}\text { Cenchrus } \\
\text { echinatus } \\
\text { (L. 1753) }\end{array}$ & Cedillo & 12 & & 11 & 1 & & NE \\
\hline Fabales & Fabaceae & $\begin{array}{l}\text { Lupinus } \\
\text { pubescens } \\
\text { (Benth. 1846) }\end{array}$ & Falso chocho & 33 & 1 & 5 & 10 & 17 & LC \\
\hline Fabales & Fabaceae & $\begin{array}{l}\text { Crotalaria } \\
\text { pumila (Ortega. } \\
\text { Standley,P.C. \& } \\
\text { Steyermark,J.A } \\
1946 \text { ) }\end{array}$ & $\begin{array}{l}\text { Tronadora, } \\
\text { Chipil }\end{array}$ & 15 & 5 & 2 & 8 & & LC \\
\hline Gentianales & Rubiaceae & $\begin{array}{l}\text { Arcytophyllum } \\
\text { thymifolium } \\
\text { (Ruiz \& Pav.) } \\
\text { (Standl, 1930) }\end{array}$ & Urañan & 6 & & & 2 & 4 & NE \\
\hline Lamiales & Plantaginaceae & $\begin{array}{l}\text { Plantago } \\
\text { linearis (Kunth, } \\
1818 \text { ) }\end{array}$ & $\begin{array}{l}\text { Llantén } \\
\text { monte }\end{array}$ & 7 & & & & 7 & NE \\
\hline Poales & Bromeliaceae & $\begin{array}{l}\text { Tillandsia } \\
\text { secunda } \\
\text { (F.W.H.von } \\
\text { Humboldt, } \\
\text { A.J.A.Bonpland } \\
\text { \& C.S.Kunth, } \\
\text { 1816) }\end{array}$ & $\begin{array}{l}\text { Huaicundo } \\
\text { paridor }\end{array}$ & 61 & & 61 & & & NE \\
\hline Poales & Cyperaceae & $\begin{array}{l}\text { Cyperus } \\
\text { polystachyos } \\
\text { (Rottb, 1773) }\end{array}$ & Flatsedge & 10 & & & 10 & & LC \\
\hline Poales & Poaceae & $\begin{array}{l}\text { Cynodon } \\
\text { dactylon } \\
\text { (Pers, 1805) }\end{array}$ & Grama fina & 1074 & 701 & $\begin{array}{l}13 \\
9\end{array}$ & 26 & $\begin{array}{l}20 \\
8\end{array}$ & NE \\
\hline Poales & Poaceae & $\begin{array}{l}\text { Pennisetum } \\
\text { clandestinum }\end{array}$ & $\begin{array}{l}\text { Kikuyo o } \\
\text { grama gruesa }\end{array}$ & 158 & & $\begin{array}{l}15 \\
8\end{array}$ & & & $\mathrm{NE}$ \\
\hline
\end{tabular}




\begin{tabular}{|c|c|c|c|c|c|c|c|c|c|}
\hline & & $\begin{array}{l}\text { (Hochst. ex } \\
\text { Chiov. 1903) }\end{array}$ & & & & & & & \\
\hline Poales & Poaceae & $\begin{array}{l}\text { Stipa ichu (Ruiz } \\
\& \text { Pav.) (Kunth } \\
\text { 1829) }\end{array}$ & Paja & 30 & & & 26 & 4 & NE \\
\hline Poales & Poaceae & $\begin{array}{l}\text { Bothriochloa } \\
\text { barbinodis } \\
((\text { Lag.) Herter, } \\
\text { 1940) }\end{array}$ & Pasto & 20 & & & & 20 & $\mathrm{NE}$ \\
\hline Poales & Poaceae & $\begin{array}{l}\text { Muhlenbergia } \\
\text { rigens ((Benth.) } \\
\text { Hitchc. } 1933)\end{array}$ & Sacama, Pasto & 108 & 24 & 3 & 60 & 21 & NE \\
\hline Poales & Poaceae & $\begin{array}{l}\text { Calamagrostis } \\
\text { sp. (Adans, } \\
1763)\end{array}$ & Pasto & 40 & 8 & 5 & 23 & 4 & NE \\
\hline Poales & Poaceae & $\begin{array}{l}\text { Avena barbata } \\
\text { (Pott ex Link. } \\
1800 \text { ) }\end{array}$ & Avena loca & 1 & & & & 1 & NE \\
\hline Polypodiales & Adiantaceae & $\begin{array}{l}\text { Pellaea } \\
\text { ternifolia (Cav.) } \\
\text { (Link. 1841) }\end{array}$ & Helecho & 1 & & & 1 & & NE \\
\hline Polypodiales & Polypodiaceae & $\begin{array}{l}\text { Campyloneuru } \\
m \text { rigidum (J. } \\
\text { Sm. 1856) }\end{array}$ & Helecho largo & 4 & & 4 & & & $\mathrm{NE}$ \\
\hline Polypodiales & Pteridaceae & $\begin{array}{l}\text { Cheilanthes } \\
\text { covillei (Maxon. } \\
\text { 1918) }\end{array}$ & Helecho común & 5 & & & 1 & 4 & $\mathrm{NE}$ \\
\hline Polypodiales & Pteridaceae & $\begin{array}{l}\text { Cheilanthes } \\
\text { bonariensis } \\
\text { (Will.) } \\
\text { (Proctor. 1953) }\end{array}$ & Helecho & 2 & 2 & & & & $\mathrm{NE}$ \\
\hline Rosales & Rosaceae & $\begin{array}{l}\text { Margyricarpus } \\
\text { pinnatus (Lam.) } \\
\text { (Kuntze. 1898) }\end{array}$ & $\begin{array}{l}\text { Piquiyuyo, } \\
\text { nigua }\end{array}$ & 15 & & 15 & & & NE \\
\hline Saxifragales & Crassulaceae & $\begin{array}{l}\text { Bryophyllum } \\
\text { crenatum } \\
\text { (Andr.) (Baker. } \\
\text { 1884) }\end{array}$ & Faroles & 4 & & & 2 & 2 & $\mathrm{NE}$ \\
\hline Saxifragales & Crassulaceae & $\begin{array}{l}\text { Crassula } \\
\text { muscosa } \\
1760)\end{array}$ & Musgo & 43 & & & 25 & 18 & NE \\
\hline Solanales & Solanaceae & $\begin{array}{l}\text { Solanum } \\
\text { nigrum (L.1753) }\end{array}$ & Hierba mora & 7 & 6 & & & 1 & NE \\
\hline Solanales & Solanaceae & $\begin{array}{l}\text { Datura } \\
\text { stramonium } \\
\text { (L.1753) }\end{array}$ & Chamico & 3 & & & 1 & 2 & NE \\
\hline Zygophyllales & Zygophyllaceae & $\begin{array}{l}\text { Tribulus } \\
\text { terrestris } \\
\text { (L.1753) }\end{array}$ & Abrojo & 17 & & 10 & 4 & 3 & NE \\
\hline
\end{tabular}

${ }^{\star} \mathrm{T} 1, \mathrm{~T} 2, \mathrm{~T} 3, \mathrm{~T} 4=$ Número de individuos por especie en cada uno de los transectos ${ }^{*} \mathrm{EC}=\mathrm{Estado}$ de conservación *UICN= Unión Internacional para la Conservación de la Naturaleza *NE= No evaluado ${ }^{*} \mathrm{LC}=$ Preocupación menor ${ }^{*} \mathrm{CR}=$ En peligro crítico

\subsection{Determinación de índices de diversidad alfa y beta del Bosque}

\subsubsection{Diversidad alfa}

\subsubsection{Estrato arbóreo}

El Bosque para el estrato arbóreo refleja una dominancia alta con un valor de 0,8367 (Simpson (1-Lambda')); las especies que dominan el estrato son: Prunus serotina (Ehrh (Cav.) Mc Vaugh, 1951- Capulí), Tecoma stans (Juss. ex Kunth 1819- Cholán) y Acacia retinodes (Schltdl.1847 -Acacia amarilla). También existe el $83 \%$ de probabilidad que dos 
individuos tomados al azar de una muestra sean de la misma especie. Adicionalmente el Bosque para el estrato arbóreo refleja una equidad media con un valor 2,068 (Shannon $\left(\mathrm{H}^{\prime}(\right.$ loge $\left.)\right)$, por cuanto se evidencia que el estrato no está representado por un mismo número de individuos. Finalmente la diversidad del estrato es media (2,534 Margalef).

\subsubsection{Estrato arbustivo}

El Bosque para el estrato arbustivo refleja una dominancia baja con un valor de 0,4441 (Simpson (1-Lambda')); las especies más representativas en el estrato son: Agave americana (Agave azul), Lantana megapotamica (Spreng. Tronc. 1974- Lantana morada), Retama sphaerocarpa (L. Boiss. 1840- Retama amarilla). También existe el $44 \%$ de probabilidad dos individuos tomados al azar de una muestra sean de la misma especie. Adicionalmente el Bosque para el estrato arbustivo refleja una equidad baja con un valor 1,079 (Shannon $\left(\mathrm{H}^{\prime}(\log \mathrm{e})\right)$, por cuanto se evidencia que el estrato no está representado por un mismo número de individuos. Finalmente la diversidad del estrato es baja $(1,811$ Margalef).

\subsubsection{Estrato herbáceo}

El Bosque para el estrato herbáceo refleja una dominancia alta con un valor de 0,7101 (Simpson (1-Lambda')); las especies que dominan el estrato son: Carpobrotus edulis (L.) N.E.Br.1926- Garra de tigre), Pennisetum clandestinum (Hochst. ex Chiov. 1903Kikuyo o grama gruesa) y Muhlenbergia rigens (Benth.) (Hitchc.1933- Sacama o pasto). También existe el $71 \%$ de probabilidad de que dos individuos tomados al azar de una muestra sean de la misma especie. Adicionalmente el Bosque para el estrato herbáceo refleja una equidad media con un valor 1,735 (Shannon $\left(\mathrm{H}^{\prime}(\log e)\right)$, por cuanto se evidencia que el estrato no está representado por un mismo número de individuos. Finalmente la diversidad del estrato es media (3,882 Margalef).

\subsubsection{Curva de acumulación}

La curva aleatorizada de acumulación de especies empleada para evaluar la eficiencia de muestreo refleja el $88,61 \%$ de eficiencia con CHAO 1, mientras que con ACE se evidencia un $90,86 \%$ de eficiencia; sin embargo, es necesario incrementar los esfuerzos de muestreos para demostrar la riqueza del lugar, tal como se indica en la Figura 3.

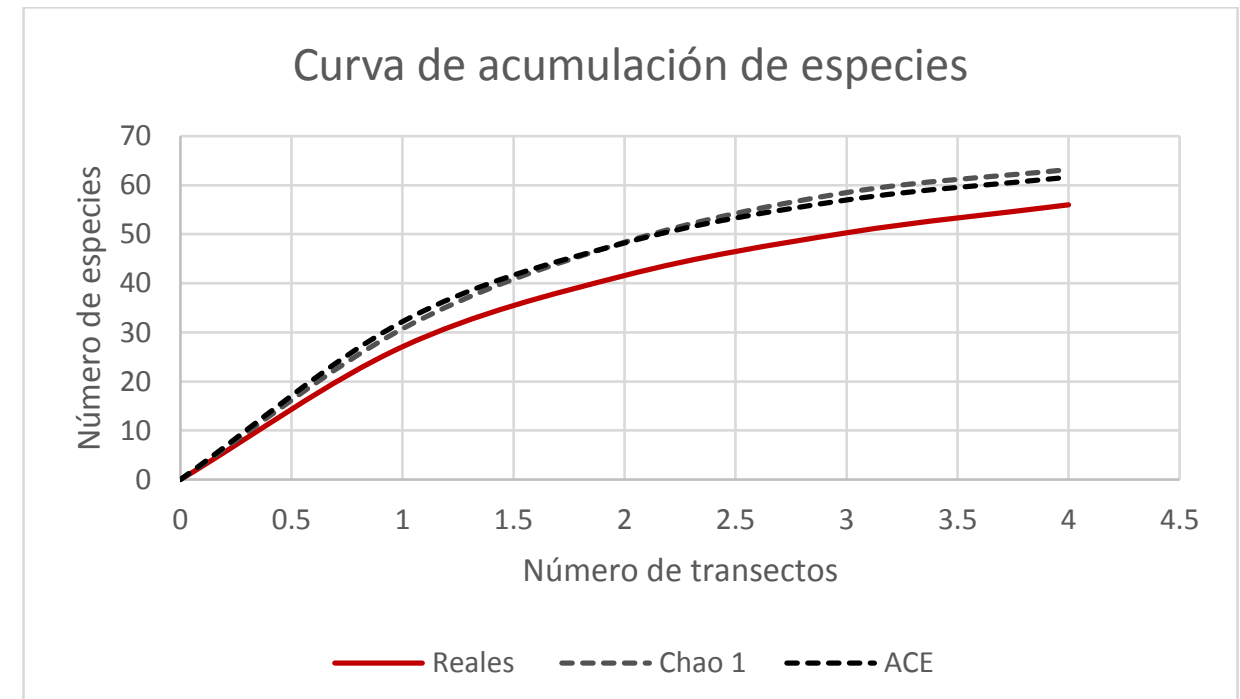

Figura 3. Curva de acumulación de especies (Fuente: Software Estimates 9,10) 


\subsubsection{Diversidad Beta}

En el Bosque Los Búhos de acuerdo con el índice de similitud de Bray- Curtis, los valores más altos se encuentran entre los transectos uno y dos con el $51,1 \%$ (con 14 especies compartidas), seguidos por los transectos tres y cuatro con el $34 \%$ (con 17 especies compartidas). Finalmente entre los transectos uno y tres, se evidencia el $10,35 \%$ de similitud (con 12 especies compartidas), tal como se muestra en las Figuras 2 y 4 .

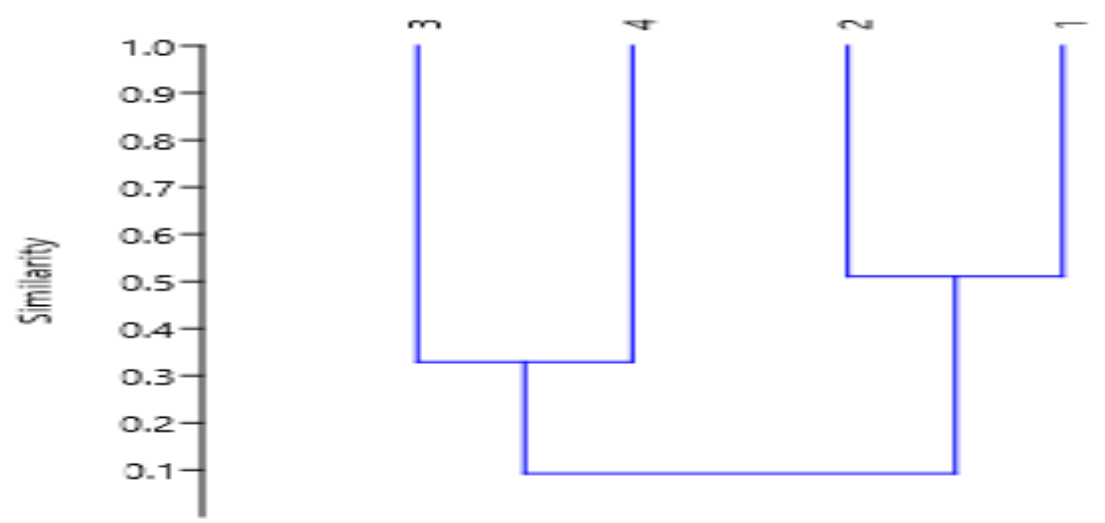

Figura 4. Dendograma de similitud de Bray-Curtis (Fuente: Software Past 3,15 )

Tabla 4. Índice de importancia de especies de flora del estrato arbóreo del Bosque Los Búhos

\begin{tabular}{|c|c|c|c|c|c|}
\hline Nombre Científico & Nombre Común & $\begin{array}{l}\text { Frecuencia } \\
\text { Relativa \% }\end{array}$ & $\begin{array}{l}\text { Densidad } \\
\text { Relativa\% }\end{array}$ & $\begin{array}{l}\text { Dominancia } \\
\text { Relativa \% }\end{array}$ & IVI \% \\
\hline $\begin{array}{l}\text { Mimosa quitensis (Benth } \\
\text { 1848) } \\
\text { Acacia retinodes (Schltdl }\end{array}$ & $\begin{array}{l}\text { Guaranga de } \\
\text { Quito }\end{array}$ & 13,636 & 9,649 & 29,727 & 17,671 \\
\hline 1847) & Acacia & 9,091 & 14,035 & 29,474 & 17,533 \\
\hline $\begin{array}{l}\text { Tecoma stans (L.) Juss. ex } \\
\text { (Kunth. 1819) }\end{array}$ & Cholán & 9,091 & 23,684 & 18,162 & 16,979 \\
\hline $\begin{array}{l}\text { Prunus serotina (Ehrh (Cav.) } \\
\text { Mc Vaugh, 1951-) }\end{array}$ & Capulí & 9,091 & 25,439 & 12,324 & 15,618 \\
\hline Callistemon citrinus (Curtis & Cepillo rojo & & & & \\
\hline Skeels. 1913) & & 9,091 & 8,772 & 4,540 & 7,468 \\
\hline Juglans nigra (L.1753) & Nogal & 9,091 & 5,263 & 0,123 & 4,826 \\
\hline Schinus molle (L.1753) & Molle & 9,091 & 2,632 & 1,025 & 4,249 \\
\hline Caesalpinia spinosa (Molina. & Guarango & & & & \\
\hline Kuntze. 1898) & & 9,091 & 1,754 & 0,474 & 3,773 \\
\hline $\begin{array}{l}\text { Acacia dealbata (Link,1822) } \\
\text { Buddleja bullata (Kunth. }\end{array}$ & Acacia fina & 4,545 & 3,509 & 2,595 & 3,550 \\
\hline $\begin{array}{l}\text { 1818) } \\
\text { Oreopanax ecuadorensis }\end{array}$ & Quishuar & 4,545 & 1,754 & 0,973 & 2,424 \\
\hline $\begin{array}{l}\text { (Seem.1865) } \\
\text { Buddleja incana (Ruiz \& Pav. }\end{array}$ & Puma maki & 4,545 & 1,754 & 0,117 & 2,139 \\
\hline $\begin{array}{l}\text { 1798) } \\
\text { Cupressus macrocarpa }\end{array}$ & Quishuar & 4,545 & 0,877 & 0,389 & 1,937 \\
\hline (Hartw. ex Gordon, 1849) & Ciprés & 4,545 & 0,877 & 0,078 & 1,833 \\
\hline TOTAL & & 100 & 100 & 100 & 100 \\
\hline
\end{tabular}




\section{3. Índice Valor de Importancia (IVI) de las especies de flora del Bosque}

\subsubsection{IVI para el estrato arbóreo}

En el Bosque las especies con el mayor valor de importancia ecológica para el estrato arbóreo acumulan el 67,78 \% del total del IVI's; las especies más representativas que contribuyen en el carácter y estructura vegetal del Bosque son: Mimosa quitensis (Benth.1848- Guaranga de quito), Acacia retinodes (Schltdl. 1847- Acacia amarilla), Tecoma stans (L.) (Juss. ex Kunth. 1819- Cholán) y finalmente Prunus serotina (Ehrh (Cav.) Mc Vaugh, 1951- Capulí), como se muestra en la Tabla 4.

\subsubsection{IVI para el estrato arbustivo}

En el Bosque las especies con el mayor valor de importancia ecológica para el estrato arbustivo acumulan el 70,35 \% del total del IVI; las especies más representativas que contribuyen en el carácter y estructura vegetal del Bosque son: Agave americana (L.1753Agave azul), Lantana megapotamica (Spreng. Tronc. 1974- Lantana morada), Retama sphaerocarpa (L. Boiss. 1840- Retama amarilla) y finalmente Opuntia cylindrica (Lam.) (DC. 1828- Tuna), tal como se muestra en la Tabla 5.

Tabla 5. Índice de importancia de especies de flora del estrato arbustivo del Bosque Los Búhos

\begin{tabular}{|c|c|c|c|c|c|}
\hline Nombre Científico & Nombre Común & $\begin{array}{l}\text { Frecuenci } \\
\text { a Relativa } \\
\%\end{array}$ & $\begin{array}{l}\text { Densidad } \\
\text { Relativa } \\
\%\end{array}$ & $\begin{array}{l}\text { Dominancia } \\
\text { Relativa \% }\end{array}$ & IVI \% \\
\hline $\begin{array}{l}\text { Dodonaea viscosa (L.) Jacq. } \\
1760\end{array}$ & Chamana & 11.11 & 2.15 & 3.22 & 5.49 \\
\hline Agave americana (L.1753) & Àgave azul & 11.11 & 65.95 & 46.27 & 41.11 \\
\hline $\begin{array}{l}\text { Opuntia cylindrica (Lam.) (DC. } \\
\text { 1828) }\end{array}$ & Cactus o Tuna & 7.41 & 2.51 & 9.07 & 6.33 \\
\hline $\begin{array}{l}\text { Cleistocactus sepium (Kunth. } \\
\text { F.A.C. Weber, 1904) }\end{array}$ & Cactus & 7.41 & 1.08 & 3.18 & 3.89 \\
\hline $\begin{array}{l}\text { Lantana megapotamica } \\
\text { (Spreng. Tronc. 1974) }\end{array}$ & Lantana morada & 18.52 & 8.96 & 16.25 & 14.57 \\
\hline $\begin{array}{l}\text { Furcraea foetida (L.) Haw } 1812 \\
\text { Opuntia soederstromiana }\end{array}$ & $\begin{array}{l}\text { Agave verde o } \\
\text { pita } \\
\text { Tuna }\end{array}$ & 11.11 & 1.43 & 3.68 & 5.41 \\
\hline $\begin{array}{l}\text { (Britton \& Rose 1919) } \\
\text { Retama sphaerocarpa (L. }\end{array}$ & Retama amarilla & 11.11 & 1.43 & 5.19 & 5.91 \\
\hline $\begin{array}{l}\text { Boiss. 1840) } \\
\text { Cortaderia Selloana (Schult. \& }\end{array}$ & & 11.11 & 3.94 & 9.97 & 8.34 \\
\hline $\begin{array}{l}\text { Schult.f.- Asch. \& Graebn. } \\
\text { 1900) } \\
\text { Dalea coerulea (L.f. Schinz \& }\end{array}$ & $\begin{array}{l}\text { Sixe o carrizo de } \\
\text { la Pampa }\end{array}$ & 3.70 & 0.36 & 1.06 & 1.71 \\
\hline Thell. 1913) & Izo & 3.70 & 0.36 & 0.35 & 1.47 \\
\hline Lantana cámara (L.1753) & Supirrosa & 3.70 & 11.83 & 1.77 & 5.77 \\
\hline TOTAL & & 100 & 100 & 100 & 100 \\
\hline
\end{tabular}

\subsubsection{IVI para el estrato herbáceo}

En el Bosque Los Búhos las especies con el mayor valor de importancia ecológica para el estrato herbáceo acumulan el $48,88 \%$ del total del IVI's, siendo las especies más representativas que contribuyen en el carácter y estructura vegetal del Bosque Carpobrotus edulis (L.) (N.E.Br. 1926- Garra de tigre), Cynodon dactylon (L. Pers, 1805Grama fina), Muhlenbergia rigens (Benth.) (Hitchc.1933- Sacama o pasto), y Calamagrostis sp. (Adans, 1763- Pasto), como se muestra en la Tabla 6. 
Tabla 6. Índice de importancia de especies de flora del estrato herbáceo del Bosque Los Búhos

\begin{tabular}{|c|c|c|c|c|c|}
\hline Nombre Científico & Nombre Común & $\begin{array}{l}\text { Frecuencia } \\
\text { Relativa \% }\end{array}$ & $\begin{array}{l}\text { Densidad } \\
\text { Relativa\% }\end{array}$ & $\begin{array}{l}\text { Dominancia } \\
\text { Relativa \% }\end{array}$ & IVI \% \\
\hline Carpobrotus edulis (L.) N.E.Br. 1926) & Garra de tigre & 4.12 & 38.74 & 7.17 & 16.68 \\
\hline $\begin{array}{l}\text { Margyricarpus pinnatus (Lam.) } \\
\text { (Kuntze. 1898) }\end{array}$ & Piquiyuyo, nigua & 1.03 & 0.51 & 0.57 & 0.70 \\
\hline $\begin{array}{l}\text { Muhlenbergia rigens ((Benth.) } \\
\text { Hitchc. 1933) }\end{array}$ & Sacama, Pasto & 13.40 & 3.67 & 19.13 & 12.07 \\
\hline Calamagrostis sp. (Adans, 1763) & Pasto & 6.19 & 1.36 & 10.13 & 5.89 \\
\hline Bidens andicola (Kunth 1820) & Ñachak & 7.22 & 1.39 & 7.15 & 5.25 \\
\hline Cynodon dactylon (L.Pers, 1805) & Grama fina & 6.19 & 36.53 & 0.00 & 14.24 \\
\hline Solanum nigrum (L. 1753) & Hierba mora & 3.09 & 0.24 & 9.51 & 4.28 \\
\hline $\begin{array}{l}\text { Gnaphalium uliginosum } \\
\text { (L.1753) }\end{array}$ & Orejas de conejo & 7.22 & 2.52 & 1.23 & 3.65 \\
\hline $\begin{array}{l}\text { Pennisetum clandestinum (Hochst. ex } \\
\text { Chiov. 1903) }\end{array}$ & $\begin{array}{l}\text { Kikuyo o grama } \\
\text { aruesa }\end{array}$ & 2.06 & 5.37 & 2.07 & 3.17 \\
\hline $\begin{array}{l}\text { Tillandsia secunda (F.W.H.von } \\
\text { Humboldt, A.J.A.Bonpland \& } \\
\text { C.S.Kunth, 1816) }\end{array}$ & $\begin{array}{l}\text { Huaicundo } \\
\text { Paridor }\end{array}$ & 1.03 & 2.07 & 2.84 & 1.98 \\
\hline $\begin{array}{l}\text { Cenchrus echinatus } \\
\text { (L. 1753) }\end{array}$ & Cedillo & 2.06 & 0.41 & 1.70 & 1.39 \\
\hline Bidens pilosa (L.1753) & Amor seco & 1.03 & 0.03 & 1.36 & 0.81 \\
\hline $\begin{array}{l}\text { Tagetes coronopifolia } \\
\text { (Willd. 1815) } \\
\text { Crotalaria pumila (Ortega. }\end{array}$ & Tagetes & 2.06 & 0.14 & 0.23 & 0.81 \\
\hline $\begin{array}{l}\text { Standley,P.C. \& Steyermark,J.A 1946) } \\
\text { Bryophyllum crenatum ((Andr.) Baker. }\end{array}$ & $\begin{array}{l}\text { Tronadora, Chipil } \\
\text { Faroles }\end{array}$ & 4.12 & 0.51 & 2.86 & 2.50 \\
\hline 1884) & & 2.06 & 0.14 & 1.70 & 1.30 \\
\hline Cheilanthes covillei (Maxon. 1918) & Helecho común & 2.06 & 0.17 & 2.84 & 1.69 \\
\hline Pellaea ternifolia (Cav.) (Link. 1841) & Helecho & 2.06 & 0.03 & 3.55 & 1.88 \\
\hline Cyperus polystachyos (Rottb, 1773) & Flatsedge & 1.03 & 0.34 & 0.43 & 0.60 \\
\hline Stipa ichu (Ruiz \& Pav.) (Kunth 1829) & Paja & 4.12 & 1.02 & 0.43 & 1.86 \\
\hline $\begin{array}{l}\text { Gnaphalium pensylvanicum } \\
\text { Bothriochloa barbinodis ((Lag.) Herter, }\end{array}$ & Macela & 1.03 & 0.03 & 7.94 & 3.00 \\
\hline 1940) & Pasto & 2.06 & 0.68 & 0.14 & 0.96 \\
\hline Avena barbata (Pott ex Link. 1800) & Avena loca & 1.03 & 0.03 & 5.11 & 2.06 \\
\hline Plantago linearis (Kunth, 1818) & Llantén de monte & 1.03 & 0.24 & 0.34 & 0.54 \\
\hline Datura stramonium (L.1753) & Chamico & 2.06 & 0.10 & 0.79 & 0.99 \\
\hline Tribulus terrestris (L.1753) & Abrojo & 3.09 & 0.58 & 0.77 & 1.48 \\
\hline Lactuca serriola (L.1756) & Lechuguilla & 1.03 & 0.03 & 2.38 & 1.15 \\
\hline $\begin{array}{l}\text { Crassula muscosa (L. 1760) } \\
\text { Cheilanthes bonariensis (Willd.) }\end{array}$ & $\begin{array}{l}\text { Musgo } \\
\text { Helecho }\end{array}$ & 2.06 & 1.46 & 0.51 & 1.34 \\
\hline (Proctor. 1953) & & 1.03 & 0.07 & 0.79 & 0.63 \\
\hline Campyloneurum rigidum (J. Sm. 1856) & Helecho largo & 2.06 & 0.14 & 1.47 & 1.22 \\
\hline $\begin{array}{l}\text { Lobularia marítima (L. Desv, 1814) } \\
\text { Arcytophyllum thymifolium }\end{array}$ & Aliso de mar & 1.03 & 0.10 & 0.45 & 0.53 \\
\hline (Ruiz \& Pav.) (Standl, 1930) & Urañan & 6.19 & 0.20 & 0.68 & 2.36 \\
\hline Lupinus pubescens (Benth. 1846) & Falso chocho & 4.12 & 1.12 & 3.74 & 3.00 \\
\hline TOTAL & & 100 & 100 & 100 & 100 \\
\hline
\end{tabular}

\section{Discusión}

El Bosque Los Búhos se encuentra intervenido y por la fisonomía, bioclima y composición florística mantiene características de la formación vegetal Estepa espinosa montano bajo (Holdrige, 1967); a esta formación (Cañadas, 1983; Sierra, 1999; y Valencia y otros, 1999) lo incluyen en Matorral seco montano y Espinar seco montano, sector valles interandinos, subregión norte y centro; y la correspondencia en (Josse, y otros, 2003) es, Bosques y arbustales xéricos interandinos montano bajos de Los Andes del Norte y en (MAE, 2013) es Bosque y arbustal semideciduo del norte de los valles-BmMn01 (Aguirre \& Medina, 2013).

Estos bosques se encuentran en áreas abiertas degradadas y son poco extensos, no continuos semiáridos y mesotérmicos. Se localizan a $2850 \mathrm{msnm}$, presentan una 
temperatura promedio de $13,9^{\circ} \mathrm{C}$, y una precipitación anual de $385,4 \mathrm{~mm}$. Así también un estudio realizado por (Carrión \& Bruzzone, 2005) identifica precipitaciones promedio de 50 $\mathrm{mm}$; y según (Acosta Solis, 1977), en estas zonas, el promedio anual de temperaturas oscila entre los 18 y $22^{\circ} \mathrm{C}$.

El suelo del Bosque Los Búhos se caracteriza por presentar bajos niveles de nitrógeno $(9,6 \mathrm{ug} / \mathrm{ml})$, niveles bajos de fósforo $(15,5 \mathrm{ug} / \mathrm{ml})$, niveles medios de materia orgánica $(4,0)$, estas variables determinan la calidad del suelo y están directamente relacionadas con la diversidad vegetal como lo afirma (Sánchez, 2012). En cuanto a rasgos vegetales, la vegetación puede ser espinosa pero las plantas armadas no dominan estas zonas (Sierra, 1999).

En el Bosque Los Búhos las familias que presentan un mayor número de especies son: Poaceae, Fabaceae, Asteraceae y Cactaceae; datos que concuerdan parcialmente con un estudio realizado en bosques montanos en Ecuador ya que se evidencia la presencia de Asteraceaes; sin embargo, difiere en la presencia de Melastomaceaes y Ericaceaes (Lozano, Bussmann, \& Kuppers, 2007).

En este tipo de ecosistema son abundantes las especies, Caesalpinia spinosa (Molina Kuntze 1898- Guarango), Dodonaea viscosa (L. Jacq. 1760- Chamana), Datura stramonium (L. 1753- Chamico), Agave americana (L.1753- Agave azul), Opuntia soederstromiana (Britton \& Rose 1919- tuna), el género Acacia y Furcraea, plantas suculentas y algunas cactáceas (Holdridge , 1967), acorde con un estudio realizado por (De La Cruz, 2004), en el cual, se evidencia que la especie Caesalpinia spinosa (Molina Kuntze 1898- Guarango) se distribuye ampliamente en esta zona de vida. Otro estudio refleja que el Estepa Espinosa Montano Bajo está conformado por grandes extensiones boscosas de Schinus molle (L. 1753- molle), Caesalpinia spinosa (Molina. Kuntze. 1898Guarango), Prosopis chilensis (Molina Stuntz, 1937- Algarrobo), Dodonaea viscosa (L. Jacq. 1760- Chamana), sin embargo difiere en las especies: Opuntia ficus-indica (L. Mil, 1996- higuera), Acacia macracantha (Humb. \& Bonpl. ex Willd. 1806- Guarango), Passiflora foetida (L. 1753- flor de la pasión), Cordia macrocephala ((Desv. Kunth. 1818- Palo negro), Mirabilis expansa (Ruiz \& Pav.) Standl. 1931- Pega pega), (Rivera \& Novoa , 2006); mientras que (Sánchez-Tello, 2011) identifica las especies Dodonaea viscosa (L. Jacq. 1760 -Chamana) y Schinus molle (L. 1753- molle) dentro de esta formación vegetal.

Al realizar los análisis de valor de importancia en función del tipo de vegetación en el Bosque Los Búhos se identificaron las siguientes especies: Mimosa quitensis (Benth. 1848- Guaranga de Quito), Acacia retinodes (Schltdl. 1847- Acacia amarilla), Tecoma stans (L.) (Juss. ex Kunth. 1819- Cholán) y Prunus serotina (Ehrh (Cav.) Mc Vaugh, 1951Capulí); en el estrato arbóreo; Agave americana (L.1753- Agave azul), Lantana megapotamica (Spreng. Tronc. 1974- Lantana morada), Retama sphaerocarpa (L. Boiss. 1840- Retama amarilla), Opuntia cylindrica (Lam.) (DC. 1828-Tuna), en el estrato arbustivo,ã y Carpobrotus edulis (L.) (N.E.Br.1926- Garra de tigre), Cynodon dactylon (L.) Pers, 1805- Grama fina), Muhlenbergia rigens (Benth.) Hitchc.1933-Sacama o pasto), Calamagrostis sp. (Adans. 1763- Pasto) para el estrato herbáceo, sin embargo no fue posible realizar comparaciones sobre esta variable entre los resultados obtenidos, con los de otros bosques estepa espinosa montano bajo, puesto que los trabajos son escasos.

\section{Conclusiones}

La composición florística del Bosque Los Búhos está formada por tres estratos, los cuales están determinados por: 13 especies, 12 familias y 11 órdenes (estrato arbóreo), 11 especies, 6 familias y 6 órdenes (estrato arbustivo), y 32 especies, 16 familias y 12 órdenes para el estrato herbáceo.

Las familias con mayor número de especies son: Fabaceae con el 30,77\% (4 especies) y Budlejaceae con el 15,38\% (2 especies) para el estrato arbóreo, Cactacea con el $27,27 \%$ (3 especies), y las familias Agavaceae, Fabaceae, Verbenaceae con el 18,18\% (2 especies cada familia) para el estrato herbáceo; finalmente con el $25 \%$ Poaceae (8 
especies), con el $18,75 \%$ Asteraceae (6 especies) y con el 6,25\% Fabaceae, Crassulaceae y Solanaceae (2 especies cada familia) para el estrato herbáceo.

El estrato arbóreo presenta una equidad media (2,068-Shannon), biodiversidad media (2,534-Margalef) y tiene dominancia alta (0,8367 -Simpson); los resultados reflejan que existe el $83 \%$ de probabilidad que dos individuos tomados al azar de una muestra sean de la misma especie. El estrato arbustivo tiene baja biodiversidad (1,811-Margalef), equidad baja (1,079 -Shannon), dominancia baja (0,4441-Simpson) además los resultados reflejan que existe el $44 \%$ de probabilidad que dos individuos tomados al azar de una muestra sean de la misma especie. Mientras que el estrato herbáceo presenta una equidad media (1,735-Shannon), biodiversidad media (3,882-Margalef) y dominancia alta $(0,7101$ Simpson), adicionalmente existe el $71 \%$ de probabilidad que dos individuos tomados al azar de una muestra sean de la misma especie.

Los valores más altos de similitud se encuentran entre los transectos 1 y 2 con el $51,1 \%$ de similitud y con 14 especies compartidas (Bray- Curtis), mientras que CHAO 1 muestra el 88,61\% de esfuerzo de muestreo; sin embargo, es necesario incrementar estos esfuerzos para consolidar la riqueza del lugar.

Las especies con altos índices de valor de importancia que contribuyen significativamente en la composición y estructura vegetal del Bosque de los Búhos en función del tipo de vegetación son: Mimosa quitensis (Benth.1848-Guaranga de Quito), Acacia retinodes (Schltdl. 1847- Acacia amarilla), Tecoma stans (L.) Juss. ex Kunth. 1819Cholán) y Prunus serotina (Ehrh (Cav.) Mc Vaugh, 1951- Capulí); (estrato arbóreo), Agave americana (L. 1753) (Agave azul), Lantana megapotamica (Spreng. Tronc. 1974- Lantana morada), Retama sphaerocarpa (L. Boiss. 1840 -Retama amarilla) y Opuntia cylindrica (Lam.) (DC. 1828-Tuna); (estrato arbustivo) y Carpobrotus edulis (L.) (N.E.Br. 1926- Garra de tigre), Cynodon dactylon (L.) Pers. 1805- Grama fina), Muhlenbergia rigens ((Benth.) Hitchc.1933- Sacama o pasto); y Calamagrostis sp. (Adans, 1763- Pasto); (estrato herbáceo).

\section{Bibliografía}

Acosta Solís. (1977). Matorral seco Montano. En Sierra R, (1999). Propuesta preliminar de un sistema de clasificación para el Ecuador continental (págs. 84-85). Quito, Ecuador: Proyecto INEFAN/GEF-BIRF y EcoCiencia.

Aguirre, Z., \& Medina, B. (2013). Bosque y Arbustal semideciduo del norte de los Valles. En Ministerio del Ambiente (2012), Sistema de clasificación de ecosistemas del Ecuador continental (págs. 153-155). Ministerio del Ambiente del Ecuador.Quito.

Blanco, A. (2017). Bosques, suelo y agua: explorando sus interacciones. Ecosistemas, 26(2): 1-9- Doi.: 10.7818/ECOS.2017.26-2.01. Disponible en: file:///C:/Users/Aracely/Downloads/1476-5292-1-PB.pdf.

Cano, Á., \& Stevenson, P. (2009). Diversidad y composición florística de tres tipos de bosque en la estación biológica Caparú, Vaupés. Bogotá: Laboratorio de Ecología de Bosques Tropicales y Primatología, Universidad de los Andes, Carrera 1 No.18A-12.

Cañadas L, (1983); Sierra R, (1999); y Valencia R, Cerón C, Palacios W, Sierra R, (1999). En Ministerio del Ambiente (2013). Matorral seco montano y Espinar seco montano, sector valles interandinos, subregión norte y centro. En Ministerio del Ambiente (2012), Sistema de clasificación de ecosistemas del Ecuador continental. Quito.

Carrión, J., \& Bruzzone, D. (2005). "Introducción a la comunidad Yacuri" p.27., en Cotahurco paseo divino. Quito: Universidad de Especialidades Turísticas-UCTp.214.

Cerón, 2003; Murillo, 2002; Moreno, 2001. Manual de Botánica Ecuatoriana Sistemática y Métodos de Estudio. Quito: Universidad Central del Ecuador.

Ceroni, A. (2003). Composición Florística y Vegetación de la Cuenca La Gallega. Morropón. Piura. Ecología Aplicada, http://www.scielo.org.pe/scielo.php?script=sci_arttext \&pid=S1726-22162003000100001. 
Cordero, D. (2011). Los bosques en América Latina. Quito, Ecuador: Oficina Regional para América del Sur de la Unión Internacional para la Conservación de la Naturaleza (UICN). Fundación Friedrich Ebert, FES-ILDI. ISBN: 978-9978-94-132-4. 24p.

De La Cruz, L. (2004). Aprovechamiento integral y racional de la Tara Caesalpinia spinosa - Caesalpinia tinctoria. Revista del Instituto de investigación FIGMMG, Vol. 7, N. ${ }^{\circ} 14$, 64-73.

Dpto. Sue. Frn- ESPOCH. (2015). Análisis físico y químico del suelo del Bosque Los Búhos. Riobamba: Espoch.

EA- ESPOCH. (2016). Datos metereológicos. Riobamba: ESPOCH.

FAO. (2009). Situación de los bosques del mundo. Roma.

FAO. (2012). El estado de los bosques del mundo. Cap 2. Los bosques y la evolución del mundo moderno. Roma: FAO: ISBN 978-92-5-307292-7. pp.64.

FAO. (2014). Evaluación de los recursos forestales mundiales 2015- Informe Nacional Ecuador. Roma.

FAO. (2015). Especies forestales leñosas arbóreas y arbustivas de los bosques montanos del Ecuador. Quito: FLACSO.

Grijalva, J., Checa, X., Ramos, R., Barrera, P., \& Limongi, R. (2012). Situación de los Recursos Genéticos Forestales - Informe País Ecuador. Preparado por el Programa Nacional de Forestería del INIAP con aval del INIAP/FAO/MAE/MAGAP/MMRREE. Ecuador: Documento sometido a la Comisión Forestal de la FAO-Roma, para preparación del Primer Informe sobre el Estado de los Recursos Genéticos Forestales en el Mundo. $95 \mathrm{p}$.

Hammer, Harper, \& Ryan. (2013). Software Past 3,15.

Hernández, P., \& Giménez, A. (2016). Diversidad, composición florística y estructura en el Chaco Serrano, Argentina. Madera y Bosques- Vol. 22, núm. 3:37-48, http://www.scielo.org.mx/scielo.php?script=sci_arttext\&pid=S140504712016000300037.

Holdridge, L. (1967). Zona de vida estepa espinosa montano bajo-Determination of World Plant Formations From Simple Climatic Dat.

IAVH. (2006). Manual de métodos para el desarrollo de inventarios de biodiversidad. Bogotá: Colombia.

INIAP. (2012). Situación de los Recursos Genéticos Forestales -Informe País-Ecuador. Preparado por el Programa Nacional de Forestería del INIAP con aval del INIAP/FAO/MAE/MAGAP/MMRREE. Documento sometido a la Comisión Forestal de la FAO-Roma, para preparación del Primer Informe sobre el Estado de los Recursos Genéticos Forestales en el Mundo. $95 \mathrm{p}$.

Josse, C., Navarro, G., Comer, P., Evans, R., Faber, D., Fellows, M., Teague, J. (2003). Bosques y arbustales xéricos interandinos montano bajos de los Andes del Norte. En Ministerio del Ambiente. (2012), Sistema de Clasificación de los ecosistemas del Ecuador continental (pág. 235). Quito.

Kutschker, A., Brand, C., \& Miserendino, L. (2009). Evaluación de la calidad de los bosques de ribera en ríos del $\mathrm{NO}$ del Chubut sometidos a distintos usos de la tierra. Ecología Austral v.19 n.1 Córdoba ene./abr. 2009, 19:19-34.

Lozano, P., Bussmann, R., \& Kuppers, M. (2007). Diversidad florística del bosque montano en el Occidente del Parque Nacional Podocarpus, Sur. Revista UDO Agrícola , 7 (1): 142-159.

Macia, M., \& Fuertes, J. (2008). Composición florística y estructura de los árboles en un bosque tropical montano de la cordillera Mosetenes, Bolivia. Revista Bolivia de Ecología y conservación ambiental, 23: 1-14,2008http://www.rjb.csic.es/jardinbotanico/ficheros/documentos/pdf/pubinv/MMB/MACIA_ RevBolEcolConAmb.pdf.

MAE. (2013). Sistema de Clasificación de los Ecosistemas del Ecuador Continental. Subsecretaría de Patrimonio Natural. Quito . 
Margalef. (1958). índice de Margalef en Métodos para medir la biodiversidad- M\&TManuales y Tesis SEA, vol. 1- 84p. Zaragoza- España: GORFI, S.A.

Mendoza, J. (2011). Estructura de la Vegetación, Diversidad y Regeneración Natural de Árboles en Bosque Seco en la Comuna El Limoncito Provincia de Santa Elena. Guayaquil, Ecuador: Escuela Superior Politécnica del Litoral - p. 135.b

Ministerio del Ambiente. (2011). Mapa Histórico de deforestación. Quito.

Ministerio del Ambiente. (2013). Especies Forestales Árboreas y Arbustivas -Bosques montanos bajos. Quito.

Moreno, C. (2001). Métodos para medir la Biodiversidad-M\&T-Manuales y Tesis SEA, vol 1. Zaragoza (España): GORFI, S.A.

Murillo, L. (2002). Medición de Biodiversidad Alfa y Beta en dos tipos de vegetación del Parque Nacional Montecristo. El Salvador: Zamorano: Escuela Agrícola Panamericana, 92p.

Pérez, R. (2017). Diversidad y composición faunística del bosque Los Búhos de la Facultad de Recursos Naturales en la Escuela Superior Politécnica de Chimborazo. Riobamba.

Quinto, H., \& Moreno, F. (2014). Diversidad florística arbórea y su relación con el suelo en un bosque pluvial tropical del chocó biogeográfico. Colombia: Universidad Nacional de Colombia sede Medellín, Medellín, Colombia.

Rivas , F., Alarcón , A., Espinosa , C., Carrillo , F., \& Villamarín, D. (2005). Formaciones vegetales en el Ecuador, Escuela Politécnica del Ejército, Facultad de Ciencias Aplicadas. Pichincha, Ecuador. Escuela de Ingeniería en Biotecnología Sangolquí.

Rivera, J., \& Novoa, S. (2006). Observaciones preliminares sobre el hábitat de Coptopteryx brevipennis Beier, 1958 en Ayacucho, Perú y notas sobre la biogeografía del género (Mantodea: Mantidae, Photininae). Rev. Perú. Entomol. 45: 19 - 25.

Ruiz, M., García, C., \& Sayer, J. (2007). Los servicios ambientales de los bosques. Ecosistemas 16 (3): 81-90.- Dpt. Ecología, Facultad Ciencias, Edificio Biológicas, Calle Darwin 2, Universidad Autónoma de Madrid, 28049-Madrid-España- Forest Conservation Programme, The World Conservation Union (IUCN), 28 rue Mauverney, $\mathrm{CH}-1196$ Gland, , https://www.revistaecosistemas.net/index.php/ecosistemas/article/ view/95.

Sánchez. (2012). "La vegetación terrestre del bosque montano de Lanchurán". Botánica Forística, Caldasia 34(1):1-24. 2012.

Sánchez-Tello, S. (2011). Zonas de vida de Cajamarca. Cajamarca - Perú.

Shannon. (1949). índice de Shannon en Métodos para medir la biodiversidad. M\&TManuales y Tesis SEA, vol. 1- 84 p. Zaragoza, España: GORFI, S.A.

Sierra, R. (1999). Propuesta preliminar de un sistema de clasificación para el Ecuador continental. Quito, Ecuador: Proyecto INEFAN/GEF-BIRF y EcoCiencia.

Simpson. (1960). Índice de Simpson en Métodos para medir la biodiversidad- M\&TManuales y Tesis SEA, vol. 1- 84p. Zaragoza, España: GORFI, S.A.

Software Estimates 9,10. (2016). Estimates: Biodiversity Estimation.

Soler, P., Berroterán, J., Gil, J., \& Acosta, R. (2012). Índice valor de importancia, diversidad y similaridad florística de especies leñosas en tres ecosistemas de los llanos centrales de Venezuela. Agronomía Trop. 62(1 - 4): 25-37. 2012, 12p.

Torres, M. (2014). Estudio Comparativo de la Composición Florística, Estructura y Diversidad de Fustales. Colombia Forestal Vol. 17(2) 203 - 229/ julio - diciembre, 2014, http://www.scielo.org.co/pdf/cofo/v17n2/v17n2a07.pdf.

Tosi, J. (1960). Zonas de vida natural en el Perú.Memoria explicativa sobre el mapa ecológico de Perú. Con un apéndice de Holdrige. Perú: Instituto Interamericano de Ciencias Agrícolas de la OEA, Zona Andina. Cap 13. párrafo 1, 2. 